\title{
Modeling Coral Reef Fish Home Range Movements in Dry Tortugas, Florida
}

\author{
Nicholas A. Farmer ${ }^{1,2}$ and Jerald S. Ault ${ }^{1}$ \\ ${ }^{1}$ Division of Marine Biology and Fisheries, Rosenstiel School of Marine and Atmospheric Science, University of Miami, \\ 4600 Rickenbacker Causeway, Miami, FL 33149, USA \\ ${ }^{2}$ Sustainable Fisheries Division, Southeast Regional Office, NOAA National Marine Fisheries Service, 263 13th Avenue South, \\ St. Petersburg, FL 33701, USA \\ Correspondence should be addressed to Nicholas A. Farmer; nick.farmer@noaa.gov
}

Received 30 August 2013; Accepted 1 October 2013; Published 16 January 2014

Academic Editors: H. A. Lessios and X. Pochon

Copyright (C) 2014 N. A. Farmer and J. S. Ault. This is an open access article distributed under the Creative Commons Attribution License, which permits unrestricted use, distribution, and reproduction in any medium, provided the original work is properly cited.

\begin{abstract}
Underestimation of reef fish space use may result in marine reserves that are too small to effectively buffer a portion of the stock from fishing mortality. Commonly used statistical home range models, such as minimum convex polygon (MCP) or 95\% kernel density (95\% KD) methods, require the exclusion of individuals who move beyond the bounds of the tracking study. Spatially explicit individual-based models of fish home range movements parameterized from multiple years of acoustic tracking data were developed for three exploited coral reef fishes (red grouper Epinephelus morio, black grouper Mycteroperca bonaci, and mutton snapper Lutjanus analis) in Dry Tortugas, Florida. Movements were characterized as a combination of probability of movement, distance moved, and turning angle. Simulations suggested that the limited temporal and geographic scope of most movement studies may underestimate home range size, especially for fish with home range centers near the edges of the array. Simulations provided useful upper bounds for home range size (red grouper: $2.28 \pm 0.81 \mathrm{~km}^{2} \mathrm{MCP}, 3.60 \pm 0.89 \mathrm{~km}^{2} \mathrm{KD}$; black grouper: $2.06 \pm$ $0.84 \mathrm{~km}^{2} \mathrm{MCP}, 3.93 \pm 1.22 \mathrm{~km}^{2} \mathrm{KD}$; mutton snapper: $\left.7.72 \pm 2.23 \mathrm{~km}^{2} \mathrm{MCP}, 6.16 \pm 1.11 \mathrm{~km}^{2} \mathrm{KD}\right)$. Simulations also suggested that MCP home ranges are more robust to artifacts of passive array acoustic detection patterns than 95\% KD methods.
\end{abstract}

\section{Introduction}

Many terrestrial and marine vertebrates use specific areas for their movements $[1,2]$. The area utilized for the majority of animal's activities and movements during certain time periods or over particular life stages is referred to as a "home range" (see review in [3]). Although numerous studies have documented home ranges for fishes (e.g., [4-9]), few have precisely quantified movements and habitat space relative to no-take marine reserve (NTMR) boundaries (but see [10]). Accurate estimates of home range size are crucial to the design of efficient NTMRs (e.g., [11-15]); an NTMR smaller than the home range size of a fish will afford it little protection from fishing pressure.

A number of statistical models have been developed to generate quantitative estimates of home range size from location data. The most commonly used methods are the minimum convex polygon method (MCP [16]), which defines the boundaries of space use and the kernel density model (KD [17]), which calculates spatial utilization probabilities. The individual's MCP or KD home range estimates generated from daily location data must reach a visible asymptote through time to be a valid estimate of home range size [16]. Within a fixed acoustic array, this assumption may create bias in resultant space-use estimates by excluding the most mobile individuals as well as individuals who are only detected at receivers placed in a straight line. Although extrapolation beyond observed values has limitations, estimating the scope of movements beyond an acoustic array in a probabilistic fashion provides a useful upper bound to empirical estimates of home range size. Underestimation of fish space requirements may lead to overconfidence regarding resource protection in the context of NTMR design [18]; 
therefore, a conservative upper bound is most appropriate for management use.

In this study, we developed a spatially explicit individualbased simulation model of coral reef fish movements within a home range, using simple inputs of move frequency, move distance, and move direction relative to home range center. These inputs were parameterized from acoustic telemetry data for groupers and snappers acquired from a broad-scale, long-term study of reef fish movements and habitat use in Dry Tortugas, Florida [10]. Using simple behavioral rules to replicate observed spatial detection frequency patterns, we explored potential biases and errors in commonly used home range estimation methods emerging from constraints on sample size, scope of the acoustic array, duration of tracking, and number of movements detected. We compared MCP and KD home ranges of each species derived from simulated movements to estimates of home ranges derived from observed movement data. We developed upper bounds for space use estimates for groupers and snappers, accounting for movements beyond the scope and duration of the acoustic tracking program.

\section{Methods}

2.1. Statistical Home Range Models. We evaluated two widely used statistical estimators of animal home range: (1) MCP and (2) KD. The basis of these methods is as follows.

The MCP is a simple heuristic "rule of thumb" model of home range. The MCP is constructed by drawing the smallest possible polygon around the observed position fixes. MCPs have been broadly used due to their computational simplicity and ease of comparison between studies, but they have been criticized for their tendency to overestimate home range size through the inclusion of unused sites [17, 19-21].

Kernel density (KD) estimation creates a histogram representation of a spatial variable (i.e., the $x$ or $y$ coordinate of a set of locations), constructed such that each point falls in the center of a sampling bin. In the simplest version of this method, the sampling bins overlap, and the points that are included in any bin are weighted according to a uniform distribution. Advanced KD methods improve this approach by replacing the uniform weighting function with a kernel function. This kernel function is a probability density function with a distribution defined by the following equation:

$$
\widehat{f}(x)=\left[\frac{1}{\left(n h^{2}\right)}\right] \sum_{i=1}^{n} K\left\{\frac{\left(\mathbf{x}-\mathbf{X}_{\mathbf{i}}\right)}{h}\right\},
$$

where $K$ is the kernel that determines the shape of the distribution that is placed over each of the points; $h$ is the bandwidth, which controls the search radius or width or the kernel; $n$ is the number of location estimates (points) used in the analysis; and $\mathbf{x}$ and $\mathbf{X}$ refer to the vectors of the coordinates of the evaluation point and all other points, respectively.

In practical applications, a grid size is selected to represent the most favorable tradeoff between resolution (and hence smoothness of the resultant probability density function) and time (coarse grids are more quickly analyzed). For our study, a grid size of $20 \mathrm{~m}$ was selected. Using the Geospatial Modeling Environment [22], a Gaussian kernel function was fit to the data. Each position fix was evaluated, and each evaluation point was in turn evaluated based on all surrounding points. Points surrounded by many other points have a high density value. To determine which surrounding points would contribute to the estimation of the density at the evaluation point, a smoothing factor (bandwidth), $h$, was used to describe the search radius about the evaluation point. Most researchers do not report cell size and bandwidths used for determining home range sizes, making it impossible to compare $\mathrm{KD}$ home ranges between studies due to the profound influence of these parameters upon the resultant home range estimates [23]. For our study, smoothed crossvalidation [24] was used to select the optimal bandwidth; this method is replicable and is believed to be robust to the overlapping position fixes commonly obtained from passive acoustic telemetry studies.

The distance from each point to the evaluation point was calculated. Based on these distances, a cumulative value was assigned to the evaluation point. This procedure was repeated until all the points in the distribution were evaluated. They were all scored and assigned density values. The values for the kernel were summed at every point on the surface. Finally, a surface was created that contained grid cell values of the kernel density estimate of the distribution. The surface was then contoured at specified volumes to give percentage home ranges (i.e., a $95 \%$ home range was contoured at $95 \%$ of the volume of the density surface-not at $95 \%$ of the area of the home range).

2.2. Home Range Model: Development. To evaluate the performance of various statistical estimators of coral reef fish home range, we developed a general stochastic spatially explicit individual-based movement model following the methods of Holgate [25] and Okubo [26]. In the model, the angle of rotation $\theta$ between the starting $\left(\mathbf{x}_{\mathbf{0}}=\left(x_{0}, y_{0}\right)\right)$ and the finishing points $\left(\mathbf{x}_{\mathbf{1}}=\left(x_{1}, y_{1}\right)\right)$ of movement in a given time interval $\Delta t$ was defined by

$$
\theta=\tan ^{-1}\left(\frac{y_{1}-y_{0}}{x_{1}-x_{0}}\right)
$$

The Euclidean distance $d$ moved by a fish between $\mathbf{x}_{\mathbf{0}}$ and $\mathbf{x}_{\mathbf{1}}$ in the time interval is

$$
d=\sqrt{\left(x_{1}-x_{0}\right)^{2}+\left(y_{1}-y_{0}\right)^{2}} .
$$

Fish home range $\mathbf{H}$ was expressed as a function of the statistical distribution of observed directions and distances of movement

$$
\mathbf{H}=\int f(\theta, \bar{\theta}) d \theta
$$

where $f(\theta, \bar{\theta}) d \theta$ is the probability of moving in direction $\theta$ biased towards the direction of the individual's home range center relative to its current position, indicated by the angle $\bar{\theta}$. The form of the home range function was expressed as a 
TABLE 1: Input parameters for individual-based mechanistic localizing tendency movement model, based on observed movements of reef fish in Dry Tortugas, Florida.

\begin{tabular}{lcccccc}
\hline Common name & $n$ & Detections & Moves & $\psi$ & $\kappa \pm$ SE & \multicolumn{1}{c}{$\lambda \pm$ SE } \\
\hline Red grouper & 44 & $2,103,428$ & 16,821 & $0.80 \%$ & $561 \pm 3$ & $3.67 \pm 0.04$ \\
Black grouper & 2 & 84,108 & 437 & $0.56 \%$ & $456 \pm 14$ & $1.19 \pm 0.09$ \\
Mutton snapper & 2 & 22,006 & 1,267 & $5.76 \%$ & $608 \pm 11$ & $3.20 \pm 0.11$ \\
\hline
\end{tabular}

Note: $n$ denotes number of fish with detected movement used to parameterize model, $\psi$ denotes probability of movement during 5 min interval, $\lambda$ denotes mean of exponential distribution of movement distances, and $\kappa$ denotes mean of von Mises distribution of turning angles between movements, relative to home range center.

general von Mises distribution that approximates a normal probability density function

$$
f(\theta, \bar{\theta})=\frac{1}{\sqrt{2 \pi} I_{0}(\kappa)} \exp [-\kappa \cos (\theta-\bar{\theta})]
$$

with two parameters governing the distribution of movement directions: a mean direction, $\bar{\theta}$, where $-\pi \leq \bar{\theta} \leq \pi$; and a concentration (variance) parameter $\kappa$ (where $\kappa \geq 0$ ). Higher values of $\kappa$ are indicative of greater home range affinity. A modified Bessel function, $I_{0}(\kappa)$, normalized $f(\theta, \bar{\theta})$ to integrate to 1.

The probability of moving from location $\mathbf{x}_{\mathbf{0}}$ to $\mathbf{x}_{\mathbf{1}}$ was expressed as probability function relating the product of the distance moved per unit time and the angle of movement:

$$
K\left(\mathbf{x}_{0}, \mathbf{x}_{1}, \Delta t\right)=\frac{f(d)}{d} f(\theta, \bar{\theta}),
$$

where $K$ is a kernel that projects the starting and finishing locations $\left(\mathbf{x}_{0}, \mathbf{x}_{1}\right)$ from Cartesian to spherical coordinates, $d$ is the absolute value of the displacement, and $\theta$ is the angle of movement between the starting and finishing points [27].

2.3. Home Range Model: Parameterization. To obtain data to parameterize the simulation model, between March 2006 and February 2008, we managed an array of 25-30 VEMCO VR2 (VEMCO Ltd., Nova Scotia, Canada; http://www .vemco.com/) hydrophone receivers in the northwestern quadrant of Dry Tortugas National Park, Florida. This array provided up to $30 \mathrm{~km}^{2}$ of acoustic coverage over a representative suite of depths and benthic reef habitats ([10] Figure 1). VEMCO V16 acoustic transmitters were surgically implanted in fish captured by hook and line ([10] Table 1). Unique receiver detection ranges were calibrated using methods detailed in Farmer et al. [28].

Over two million acoustic detections were registered for several species of tagged coral reef fish (Table 1). Red grouper, Epinephelus morio $(n=45)$, were the primary emphasis for this study, with sensitivity runs performed using parameterizations from the movements of opportunistically tagged black grouper, Mycteroperca bonaci $(n=3)$, and mutton snapper, Lutjanus analis $(n=3)$. To mitigate the potential impacts of transmitter signal collisions, tags were set with random delay times of 30-180 sec, and fewer than 5 fish were tagged at any given location. Model-weighted mean position estimates generated on 5-min batching intervals were considered optimal, following Farmer and Ault [10] and Farmer et al. [28].

For our home range model input parameters to be representative of population trends, it was important that individual fish were not overrepresented. Theoretically, risk of overrepresentation in the input parameters for the model would be higher for fish with longer tracking durations or higher total detections. To quantitatively identify minimal standards for tracking duration or number of detections and to evaluate the influence of individual fish (Table 1) on input parameters, the relationships between red grouper estimated home ranges and number of detections, number of detected moves and tracking duration were evaluated using linear regression models [29], with fish ID as a random factor. Additional linear regressions were used to test for relationships between days tracked versus number of detected moves, and total detections versus number of detected moves. A significant relationship between any of these combinations of variables would suggest that parameterization of home range models might be overly influenced by a limited subset of actively moving fish.

A custom Java 6.10 algorithm was developed to process time-sequenced observed reef fish movements paths ("observed") to estimate distances from previous positions, $d_{\text {prev }}$; distances from home range center, $d_{\text {centroid }}$; and turning angles, $\theta$, between movements, relative to angle to home range centroid, $\bar{\theta}$. Data were pooled within species. Movements were expressed as a three-step process: (1) a probability of moving during the interval, (2) a distance moved, and (3) a direction moved (if movement occurred). Movement distances were modeled using "Input Analyzer for Arena" (Rockwell Automation, Warrendale, PA) to determine the best fit probability distribution for $d_{\text {prev }}$. Species-specific aggregated turning angles relative to home range center $(\theta-\bar{\theta})$ were fit to von Mises distributions with the "Circular" package in $\mathrm{R}$ (http://www.r-project.org/).

The sensitivity of the model parameterization to lower sample sizes was evaluated in two ways. First, to test the impacts of only low sample size, 1000 bootstrapped samples of 437 randomly selected movement observations from all red grouper movement observations $(n=16,821)$ were fit to exponential distributions, and the mean was compared to the mean for an exponential distribution fit to all red grouper observations. This threshold was selected because only 437 movements were observed from two black grouper. Because meaningful movement data were only obtained from two black grouper and two mutton snapper, the impacts of 


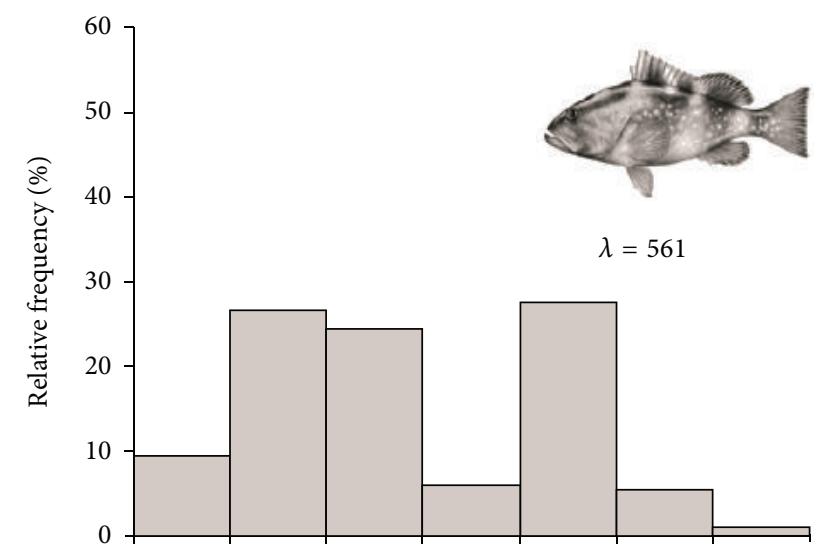

(a)

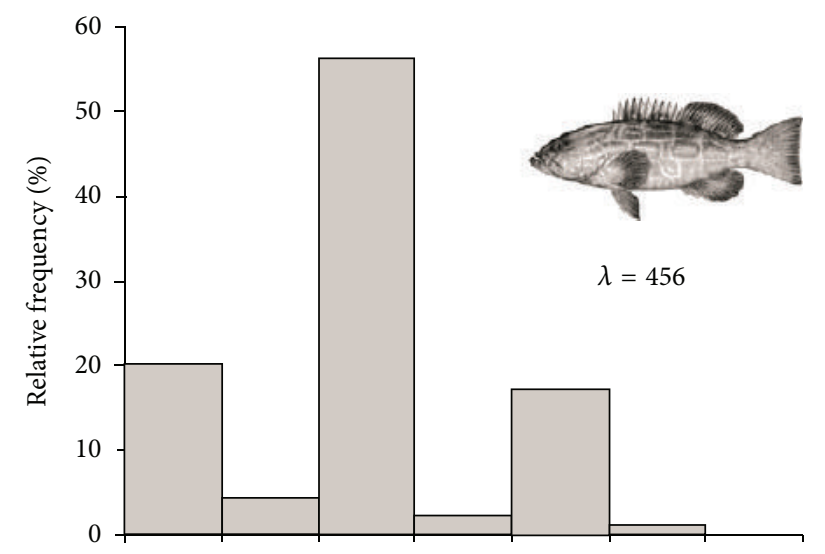

(b)

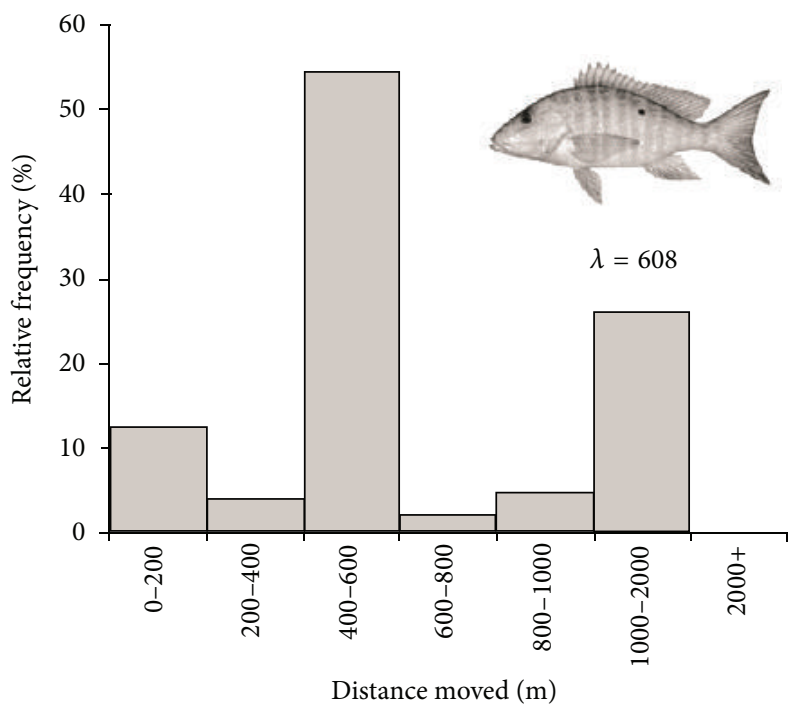

(c)

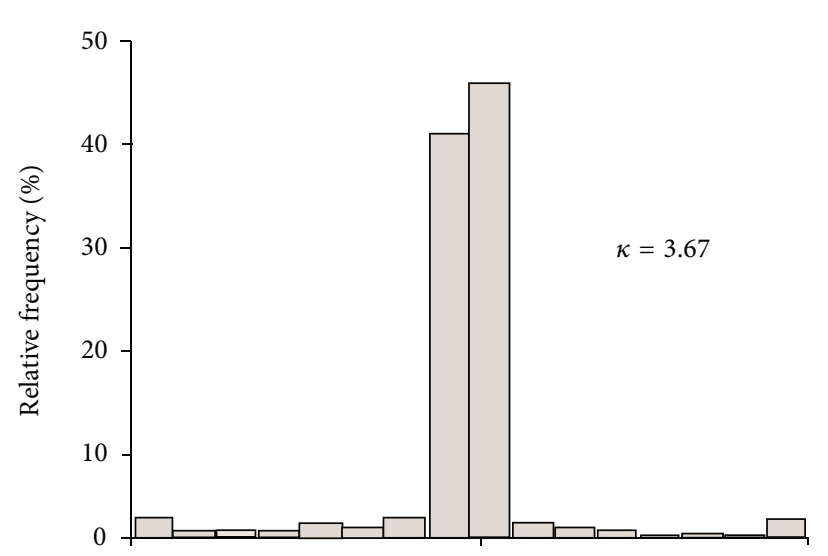

(d)

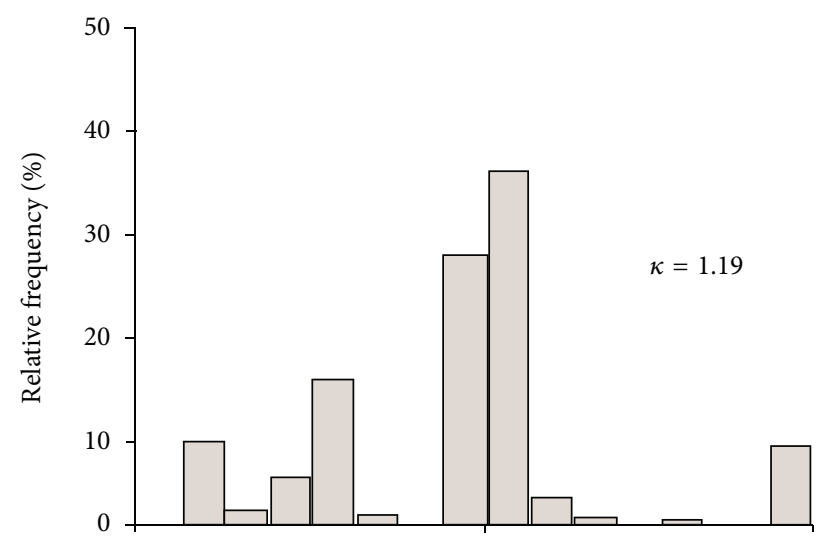

(e)

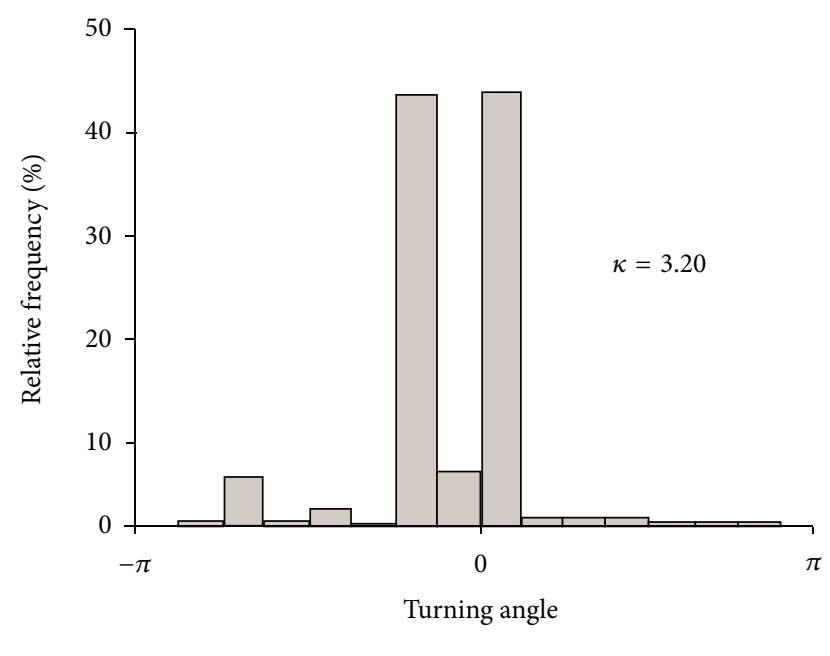

(f)

FIGURE 1: Relative frequency histograms of observed (a)-(c) nonzero movements and (d)-(f) turning angles relative to home range center for ((a), (f)) all tracked red grouper (Epinephelus morio), ((b), (e)) black grouper (Mycteroperca bonaci), and ((c), (f)) mutton snapper (Lutjanus analis). Means $(\lambda)$ of exponential distribution of movement distance and concentration parameter $(\kappa)$ of von Mises distribution of turning angles are provided on figures. Fish illustrations copyright Diane Rome Peebles. 
a limited number of individuals upon model parameterization was also tested. To test the impacts of having movement observations from a limited number of individuals, two observed red grouper were randomly selected, and 500 bootstrapped samples of 437 randomly selected observed movements were fit to exponential distributions. This test was iterated 100 times, and the mean across iterations was compared to the mean for an exponential distribution fit to all red grouper observations.

2.4. Home Range Model: Simulation Runs. Simulated movement paths and detection sequences were generated using a spatially explicit model implemented in Java 6.10 using the Repast Agent-based Modeling Toolkit [30, 31]. This model parsed the Dry Tortugas, Florida, region into 22,620 cells of $200 \mathrm{~m}$ by $200 \mathrm{~m}$ size. Each cell was assigned a unique identification code and depth. An array of simulated receivers was implemented in grid cells corresponding to the locations of receivers described in Farmer and Ault [10]. For each simulation run, fish were instantiated with home ranges centered atop each of the simulated receivers.

For simulations, if a random number drawn from a uniform distribution between 0 and 1 was less than the probability of moving a discernible distance $(\psi)$ in a $5 \mathrm{~min}$ interval, a movement distance was randomly drawn from the exponential distribution with mean $(\lambda)$ fit to $d_{\text {prev }}$. Maximum movement distance was bounded at $6000 \mathrm{~m}$ per move, as sustained swimming speeds above $72 \mathrm{~km} \cdot \mathrm{h}^{-1}$ (45 mph) were deemed unrealistic for reef fish. Movement distances were converted from meters to simulation grid cell units (i.e., $200 \mathrm{~m}$ units). Movements of $<200 \mathrm{~m}$ (i.e., grid cell distance $<1$ unit) were beneath the spatial resolution of the position estimates emerging from the telemetry data [28] and were considered negligible. Turning angles relative to home range center were randomly selected from a von Mises distribution with the concentration parameter $\left(\kappa_{\tau}\right)$ for the species under examination.

A simulated array of receivers was used to provide more accurate comparisons between empirical and simulated data. The number of detections registered by a simulated receiver during a given interval for each fish was computed by dividing the length of the interval by the ping rate and then multiplying by the probability of detection at distance [28]. Simulated movements ("Sim-Actual") and detection patterns ("SimDetect") were recorded for one year.

2.5. Home Range Models: Evaluation. Observed and simulated detections were postprocessed using a model-weighted harmonic mean positioning estimator $[10,28]$ which increased positioning resolution during intervals when detections were recorded at multiple receivers. Home ranges of observed and simulated fish were compared. MCP and 95\% KD home ranges were computed for "Observed," "Sim-Detect," and "Sim-Actual" position fixes using Geospatial Modeling Environment [22]. KD home ranges were computed using smoothed cross-validation (SCV) bandwidth estimation and a cell size of $20 \mathrm{~m}$. The spatial distribution of error introduced into empirical studies by fish movements beyond the bounds of the array was evaluated by comparing "Sim-Detect" and
"Sim-Actual" home ranges for fish with home range centers at core and peripheral receivers. Receivers were defined as "peripheral" if they were not completely surrounded by other receivers.

Although it is broadly accepted that an empirical home range estimate should only be considered reliable if an asymptote is present when estimated home range size is plotted against tracking duration, little guidance exists in the literature regarding minimum tracking duration or detections, what percent change in home range size constitutes a "useful" asymptote, or how to account for likelihood of movements beyond the study area (e.g., "peripheral effects"). To explore the sensitivity of empirical home range estimates to these criteria, we computed MCP and KD home ranges for observed fish under a variety of filters. We also developed a generalized linear mixed model using SAS Proc GLIMMIX (SAS Institute, Inc., Cary, NC) to test the relationship between percentage of final estimated red grouper home range size versus the fixed effect of tracking duration (months) and random effects of individual and interaction effects. Additionally, estimated home range size for simulated fish was plotted against months of simulated observation to examine asymptotic characteristics.

\section{Results}

3.1. Home Range Model: Parameterization. Input data did not appear significantly biased towards overestimation of movement due to an overabundance of sampling points from fish with large home ranges. No trends were detected between observed red grouper home ranges and number of detections or moves $(P>0.05)$, days tracked and number of moves detected $\left(F_{1,42}=0.79, P>0.05\right)$, or total detections and number of moves detected $\left(F_{1,42}=1.02, P>0.05\right)$. These results suggest that simulation model input parameters were relatively insensitive to the length of observation. By contrast, a slightly declining trend between days tracked and observed red grouper home range size $\left(\beta=-0.01, F_{1,42}=9.75, P<\right.$ 0.01 ) was detected, suggesting that fish leaving the acoustic array shortly after tagging may have been transient fish, may have been transitioning between different home ranges, or may have been behaviorally impacted by the tagging process. Regression models failed to identify quantitative thresholds for tracking duration, number of detections, or number of moves for estimating a home range. However, when the analysis of home range size versus days tracked was restricted to observed red grouper exhibiting an asymptotic home range size estimate and with a home range center towards the middle of the acoustic array (i.e., "low peripheral effects"), the relationship between days tracked and home range size was eliminated $\left(F_{1,11}=2.10, P>0.05\right)$. This finding implies that home range estimates of these individuals was robust to sampling duration but may also suggest that the common practice of restricting home range estimates to fish meeting the asymptotic assumption may underestimate mean space requirements by excluding more mobile individuals from consideration.

Input parameters for the home range model are presented in Table 1. Empirical observations of reef fish movements 
Observed

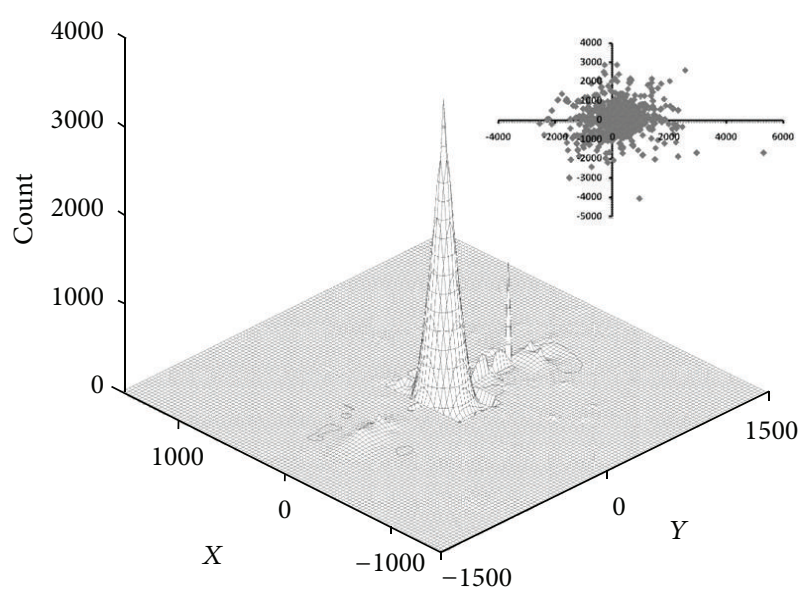

(a)
Simulated (observed $n)$

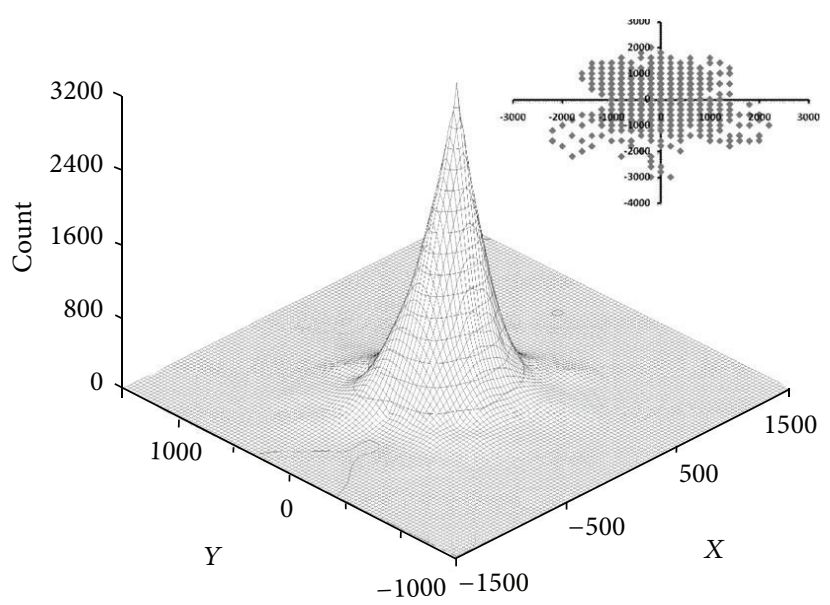

(b)

FIGURE 2: Distribution of spatial positions relative to home range center ( $\mathrm{m}$ ) for (a) observed and (b) simulated red grouper, aggregated across all individuals. Insets show two-dimensional distribution of position fixes. Simulation output is shown for movements corresponding to empirical sample size.

indicated that red grouper and black grouper moved infrequently ( $<1 \%$ of 5 min intervals) as compared to mutton snapper $(5.76 \%)$. For all three species, exponential distributions provided the best fits with the lowest mean square error to the nonzero movement data (Table 1, Figure 1); however, some multimodality was evident in the distribution of distances moved, resulting in relatively poor fits $(P<0.05)$. The best fit von Mises distributions for turning angles are displayed in Figure 1. The von Mises concentration parameter was three times higher for red grouper versus black grouper, suggesting a comparatively stronger association with a home range center for red grouper.

The observed spatial distribution of movements relative to home range centers was reasonably captured by the simulation (Figure 2); however the emergent pattern from the "Sim-Detect" movements was more circular and uniform than the real-world pattern. The shape of the distribution was controlled by the interplay of the two movement parameters $\left(\lambda, \kappa_{\tau}\right)$; the magnitude of the distribution was controlled by the frequency of movement $(\psi)$ and the number of individuals tracked. For black grouper and mutton snapper, the shapes of the simulated distributions were very similar to those observed. For red grouper, the shape of the observed distribution was more heavily concentrated on the home range center than that of the simulated distribution. The largest movement observed for red grouper was slightly less than $600 \mathrm{~m}$.

Small sample sizes appeared to have little impact on movement model fits, provided that they were randomly sampled and representative of the population; there was no significant difference $(P>0.05)$ between the exponential distribution fit mean $(\lambda)$ based on 16,821 red grouper movement observations $(561.4 \pm 2.8)$ and the exponential distribution fit $\lambda$ based on 1000 bootstrapped samples of 437 randomly selected red grouper observations (560.6 \pm
0.55). However, if movements were not representative of the population, model parameterization could be heavily skewed; there was a substantial difference between the exponential distribution fit $\lambda$ based on 500 bootstrapped samples of 437 randomly selected red grouper observations drawn from 100 randomly selected pairs of observed red grouper (747.15 \pm 34.4; range 288.4-2260.3) and the exponential distribution fit mean $(\lambda)$ based on all 16,821 red grouper observed movements $(561.4 \pm 2.8)$. These findings suggest that the relatively low number of observed movements for the two observed black grouper and two observed mutton snapper may provide reasonable movement model fits, but only if the distributions of movement distances for those individuals were representative of the population. As this assumption was unlikely to be met, subsequent statistics for mutton snapper and black grouper are provided for contrast to red grouper only and should not be interpreted as representative of a population mean.

3.2. Home Range Models: Evaluation. Mean MCP and $95 \%$ $\mathrm{KD}$ home range estimates for "Observed," "Sim-Detect," and "Sim-Actual" fish positions are shown in Table 2. KD home range estimates could not be generated for some fish due to an overabundance of detections at 1-2 sites impairing SCV bandwidth estimator performance. MCP and 95\% KD home range estimates differed substantially within species. MCP home range estimates for mutton snapper were larger than those of red grouper and black grouper for all three groups. Surprisingly, red grouper observed $95 \%$ KD home ranges were larger than those of mutton snapper or black grouper. By contrast, mutton snapper had the largest "Sim-Actual" and "Sim-Detect" 95\% KD home ranges. MCP home range estimates appeared to be more robust to the detection limitations of the array, as there was substantially less deviation between MCP home range estimates across the three groups for each 
TABLE 2: Estimated home range areas $\left(\mathrm{km}^{2}\right)$ for empirically observed red grouper, black grouper, and mutton snapper compared to home range areas from simulated detection patterns and actual paths for simulated fish, with difference between simulated and simulated detection home range sizes.

\begin{tabular}{|c|c|c|c|c|c|c|c|c|c|}
\hline \multirow[b]{2}{*}{ Species } & \multirow[b]{2}{*}{ Stat } & \multicolumn{4}{|c|}{ Minimum convex polygon (MCP), home range $\left(\mathrm{km}^{2}\right)$} & \multicolumn{4}{|c|}{ Kernel density (95\% KD), home range $\left(\mathrm{km}^{2}\right)$} \\
\hline & & Observed & Simulated & $\begin{array}{l}\text { Simulated } \\
\text { detections }\end{array}$ & $\begin{array}{c}\text { Simulated-simulated } \\
\text { detections }\end{array}$ & Observed & Simulated & $\begin{array}{l}\text { Simulated } \\
\text { detections }\end{array}$ & $\begin{array}{c}\text { Simulated-simulated } \\
\text { detections }\end{array}$ \\
\hline \multirow{4}{*}{ Red grouper } & Mean & 2.09 & 2.28 & 2.49 & -0.19 & 1.71 & 3.60 & 7.72 & -4.12 \\
\hline & sd & 2.04 & 0.81 & 1.58 & 1.85 & 0.48 & 0.89 & 4.69 & 4.75 \\
\hline & $n$ & 29 & 32 & 30 & 30 & 29 & 32 & 29 & 29 \\
\hline & se & 0.38 & 0.14 & 0.29 & 0.34 & 0.09 & 0.16 & 0.87 & 0.88 \\
\hline \multirow{4}{*}{ Black grouper } & Mean & 1.44 & 2.06 & 1.84 & 0.34 & 0.24 & 3.93 & 7.16 & -3.42 \\
\hline & sd & 1.48 & 0.84 & 1.33 & 1.65 & 0.12 & 1.22 & 4.70 & 4.79 \\
\hline & $n$ & 2 & 32 & 30 & 32 & 2 & 32 & 29 & 29 \\
\hline & se & 1.05 & 0.15 & 0.24 & 0.29 & 0.08 & 0.22 & 0.87 & 0.89 \\
\hline \multirow{4}{*}{ Mutton snapper } & Mean & 7.64 & 7.72 & 5.55 & 2.17 & 0.58 & 6.16 & 8.01 & -1.85 \\
\hline & $\mathrm{r} s \mathrm{~d}$ & - & 2.23 & 3.06 & 3.67 & - & 1.11 & 3.80 & 4.14 \\
\hline & $n$ & 1 & 32 & 32 & 32 & 1 & 32 & 32 & 32 \\
\hline & se & - & 0.39 & 0.54 & 0.65 & - & 0.20 & 0.67 & 0.73 \\
\hline
\end{tabular}

of the species. The $95 \%$ KD estimates for the "Sim-Detect" group were overinflated relative to the "Sim-Actual" estimate; this may indicate the undesirable influence of repeated observations at the same site, as well as reduced position estimates at interreceiver locations. By contrast, MCP home ranges for the "Sim-Detect" group were underestimated due to the lack of peripheral detections. The distinction between the MCP and 95\% KD home range estimation methods was most pronounced for mutton snapper, the most mobile species evaluated. Long distance movements generated a large MCP for this species, but the 95\% KD for observed mutton snapper was smaller than that for observed red grouper. Interestingly, 95\% KD estimates for the "Sim-Actual" group were larger than MCP estimates for red grouper and black grouper.

Paired $t$-tests for means between "Sim-Actual" and "SimDetect" MCPs indicated that 12-month home ranges were consistently underestimated by the simulated acoustic array for black grouper $(t=-2.43, \mathrm{df}=30$, and $P<0.05)$ and mutton snapper $(t=-6.37, \mathrm{df}=30$, and $P<0.001)$ but not red grouper $(t=-1.24, \mathrm{df}=30$, and $P>0.05)$. This suggests that acoustic array configuration was adequate for red grouper home range estimation. A comparison of 100\% MCP and 95\% KD home range areas for "Sim-Detect" versus "SimActual" paths showed relatively minor differences for red grouper and black grouper; however, mutton snapper "SimActual" MCPs were substantially larger than those computed from simulated detections, suggesting frequent, broad-scale movements out of the simulated array.

Location of the home range center with respect to the configuration of the acoustic array influenced "Sim-Detect" home range size relative to "Sim-Actual" home ranges. Simulated receivers tended to overestimate home ranges for fish with home range centers in the core of the array and underestimate home ranges for fish with home range centers on the periphery of the array (Figure 3). One-tailed twosample $t$-tests assuming equal variances revealed significantly underestimated home range sizes for red grouper $(t=-2.41$, $\mathrm{df}=29$, and $P<0.001)$, black grouper $(t=-3.82, \mathrm{df}=29$, and $P<0.001)$, and mutton snapper $(t=-1.96$, $\mathrm{df}=29$, and $P<0.05$ ) with home range centers along the edges of the acoustic array versus those with home range centers in the core of the array. The configuration of the acoustic array may also distort the shapes and sizes of $\mathrm{KD}$ home ranges; comparisons between "Sim-Detect" and "Sim-Actual" KD home ranges showed "Sim-Detect" KD home ranges to be linearly distorted corresponding to receiver locations and overextended into the periphery relative to analogous "SimActual" KD home ranges (Figure 4).

Home range estimates for individual observed tagged fish are presented in Table 3. Various filtering criteria were applied to home range estimates to explore sensitivity of speciesspecific home range estimates (Table 4 ). The most conservative filter (Table 4: bold) resulted in substantial increases in estimated home range for black grouper, no estimate for mutton snapper, and minimal changes for red grouper despite cutting sample size by over $50 \%$. This analysis suggests that a large sample size (i.e., many tagged individuals) and a conservative filter likely provide the most robust home range estimates for fish remaining within the acoustic array. Tracking duration was a significant factor in estimated MCP home range size. Mean tracking duration from Farmer and Ault [10] was approximately three months. Least squares mean estimates generated from a mixed model regression of the percent of final MCP home range size versus months of tracking indicated that the most observed red grouper would reach nearly $100 \%$ of their final estimated home range size after 2-3 months of observation (Figure 5).

\section{Discussion}

Home range modeling approaches are generally of three types [32, 33]: (1) analytical modeling derived from statistical 
TABLE 3: Empirical movement and home range (MCP: minimum convex polygon; KDE: kernel density estimate; $\mathrm{km}^{2}$ ) estimates from acoustically tracked red grouper (RG), black grouper (BG), and mutton snapper (MS) in Dry Tortugas, Florida.

\begin{tabular}{|c|c|c|c|c|c|c|c|c|c|c|c|}
\hline \multirow{2}{*}{ Species } & \multirow{2}{*}{ ID } & \multirow{2}{*}{ Total length $(\mathrm{cm})$} & \multirow{2}{*}{ Peripheral effect } & \multirow{2}{*}{ Days tracked } & \multirow{2}{*}{ Asymptote } & \multicolumn{2}{|c|}{ Home range $\left(\mathrm{km}^{2}\right)$} & \multirow{2}{*}{ Detections } & \multirow{2}{*}{$\%$ total } & \multirow{2}{*}{ Moves } & \multirow{2}{*}{$\%$ total } \\
\hline & & & & & & MCP & $95 \% \mathrm{KD}$ & & & & \\
\hline RG & 36 & 64 & Moderate & 18 & No & 8.16 & 12.21 & 2,198 & $0.1 \%$ & 300 & $1.8 \%$ \\
\hline RG & 37 & 47 & Low & 179 & Yes & 0.47 & 0.10 & 64,672 & $3.1 \%$ & 85 & $0.5 \%$ \\
\hline RG & 41 & 47 & Low & 179 & Yes & 0.44 & 0.09 & 75,732 & $3.6 \%$ & 61 & $0.4 \%$ \\
\hline RG & 42 & 48 & Low & 179 & Yes & 0.93 & 0.07 & 21,823 & $1.1 \%$ & 484 & $2.9 \%$ \\
\hline RG & 47 & 48 & Moderate & 11 & No & 12.3 & 17.16 & 1,534 & $0.1 \%$ & 57 & $0.3 \%$ \\
\hline RG & 51 & 66 & Low & 157 & Yes & 1.95 & 0.17 & 12,329 & $0.6 \%$ & 1149 & $6.8 \%$ \\
\hline RG & 170 & 61 & High & 93 & No & Linear & Linear & 705 & $0.0 \%$ & 11 & $0.1 \%$ \\
\hline RG & 171 & 60 & High & 98 & Yes & 0.64 & 4.89 & 2,359 & $0.1 \%$ & 23 & $0.1 \%$ \\
\hline RG & 172 & 49 & High & 3 & No & 5.14 & 7.39 & 471 & $0.0 \%$ & 29 & $0.2 \%$ \\
\hline RG & 173 & 49 & Moderate & 92 & Yes & 1.28 & 4.44 & 611 & $0.0 \%$ & 116 & $0.7 \%$ \\
\hline RG & 175 & 53 & Moderate & 96 & No & Linear & Linear & 5,190 & $0.3 \%$ & 8 & $0.0 \%$ \\
\hline RG & 176 & 55 & High & 93 & Yes & 0.64 & 3.21 & 4,512 & $0.2 \%$ & 32 & $0.2 \%$ \\
\hline RG & 177 & 50 & High & 89 & No & Linear & Linear & 373 & $0.0 \%$ & 6 & $0.0 \%$ \\
\hline RG & 178 & 65 & High & 90 & No & Linear & Linear & 2,591 & $0.1 \%$ & 193 & $1.1 \%$ \\
\hline RG & 179 & 57 & Moderate & 23 & Maybe & 7.39 & 19.90 & 244 & $0.0 \%$ & 36 & $0.2 \%$ \\
\hline RG & 180 & 55 & Moderate & 40 & Maybe & 3.19 & 12.17 & 380 & $0.0 \%$ & 93 & $0.6 \%$ \\
\hline RG & 181 & 49 & High & 13 & Maybe & 1.97 & 4.07 & 883 & $0.0 \%$ & 38 & $0.2 \%$ \\
\hline RG & 183 & 48 & High & 98 & Yes & 3.22 & 0.01 & 8,491 & $0.4 \%$ & 1325 & $7.9 \%$ \\
\hline RG & 184 & 55 & Low & 43 & Yes & 1.91 & 1.06 & 4,915 & $0.2 \%$ & 848 & $5.0 \%$ \\
\hline RG & 185 & 55 & Low & 43 & Yes & 1.9 & 0.66 & 8,895 & $0.4 \%$ & 171 & $1.0 \%$ \\
\hline RG & 186 & 51 & Moderate & 91 & Yes & 3.49 & 0.55 & 12,327 & $0.6 \%$ & 1259 & $7.5 \%$ \\
\hline RG & 187 & 50 & Low & 92 & Yes & 1.89 & 1.31 & 4,806 & $0.2 \%$ & 965 & $5.7 \%$ \\
\hline RG & 190 & 62 & High & 101 & Yes & Linear & Linear & 55,093 & $2.7 \%$ & 25 & $0.1 \%$ \\
\hline RG & 191 & 51 & High & 93 & Yes & 0.63 & 0.85 & 36,329 & $1.8 \%$ & 38 & $0.2 \%$ \\
\hline RG & 194 & 54 & High & 94 & Maybe & 1.55 & 0.88 & 12,928 & $0.6 \%$ & 106 & $0.6 \%$ \\
\hline RG & 862 & 54 & Very high & 86 & Maybe & 0.92 & 1.00 & 73,728 & $3.6 \%$ & 26 & $0.2 \%$ \\
\hline RG & 863 & 51 & High & 95 & Yes & 0.31 & 5.32 & 6,728 & $0.3 \%$ & 7 & $0.0 \%$ \\
\hline RG & 864 & 55 & High & 92 & No & Linear & Linear & 44,890 & $2.2 \%$ & 892 & $5.3 \%$ \\
\hline RG & 865 & 56 & High & 33 & Yes & 1.28 & 0.39 & 14,616 & $0.7 \%$ & 1027 & $6.1 \%$ \\
\hline RG & 866 & 53 & High & 66 & No & Linear & Linear & 424 & $0.0 \%$ & 73 & $0.4 \%$ \\
\hline RG & 867 & 55 & High & 89 & Yes & 0.49 & 0.12 & 42,058 & $2.0 \%$ & 2687 & $16.0 \%$ \\
\hline RG & 868 & 49 & High & 88 & No & Linear & Linear & 24,533 & $1.2 \%$ & 489 & $2.9 \%$ \\
\hline RG & 869 & 60 & High & 87 & No & Linear & Linear & 21,703 & $1.0 \%$ & 2978 & $17.7 \%$ \\
\hline RG & 870 & 45 & High & 25 & Yes & 2.2 & 2.25 & 2,528 & $0.1 \%$ & 354 & $2.1 \%$ \\
\hline RG & 871 & 57 & High & 76 & No & Linear & Linear & 400 & $0.0 \%$ & 103 & $0.6 \%$ \\
\hline RG & 872 & 53 & High & 79 & Yes & 0.49 & 0.19 & 70,316 & $3.4 \%$ & 77 & $0.5 \%$ \\
\hline RG & 873 & 48 & Low & 280 & Yes & 6.44 & 0.01 & 199,933 & $9.6 \%$ & 5 & $0.0 \%$ \\
\hline RG & 874 & 60 & Low & 278 & Yes & 1.4 & 0.12 & 313,240 & $15.0 \%$ & 173 & $1.0 \%$ \\
\hline RG & 875 & 52 & Low & 280 & Yes & 1.68 & 0.69 & 205,442 & $9.9 \%$ & 29 & $0.2 \%$ \\
\hline RG & 877 & 57 & Low & 280 & Yes & 0.83 & 0.33 & 124,104 & $6.0 \%$ & 93 & $0.6 \%$ \\
\hline RG & 878 & 48 & Moderate & 44 & Yes & 5.76 & 2.96 & 21,144 & $1.0 \%$ & 201 & $1.2 \%$ \\
\hline RG & 880 & 49 & Low & 269 & Yes & 2.59 & 4.38 & 35,437 & $1.7 \%$ & 14 & $0.1 \%$ \\
\hline RG & 881 & 50 & Low & 280 & Yes & 9.17 & 1.64 & 261,025 & $12.6 \%$ & 27 & $0.2 \%$ \\
\hline RG & 884 & 53 & Low & 280 & Yes & 1.68 & 0.25 & 272,798 & $13.1 \%$ & 108 & $0.6 \%$ \\
\hline $\mathrm{BG}$ & 43 & 75 & Low & 179 & Yes & 2.48 & 0.12 & 72,644 & $86.4 \%$ & 410 & $93.8 \%$ \\
\hline $\mathrm{BG}$ & 174 & 50 & High & 91 & Yes & 0.39 & 0.35 & 11,466 & $13.6 \%$ & 27 & $6.2 \%$ \\
\hline MS & 50 & 43 & High & 4 & No & 0.19 & 0.23 & 183 & $0.8 \%$ & 39 & $3.1 \%$ \\
\hline MS & 53 & 70 & Moderate & 168 & Yes & 7.64 & 0.58 & 21,825 & $99.2 \%$ & 1228 & $96.9 \%$ \\
\hline
\end{tabular}

Note: $\mathrm{KDE}$ bandwidths $(x, y$, and $x y$ covariance $)$ available upon request. 


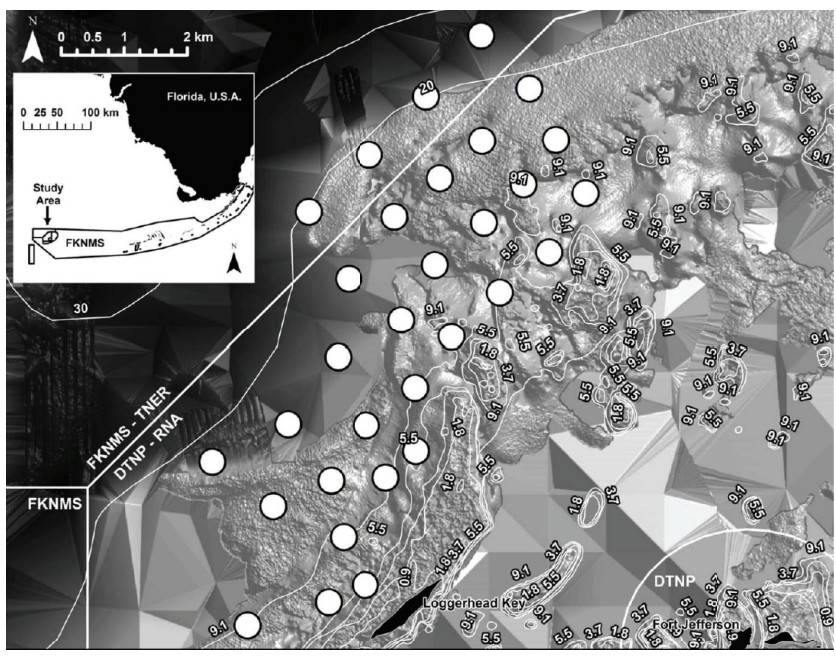

(a)

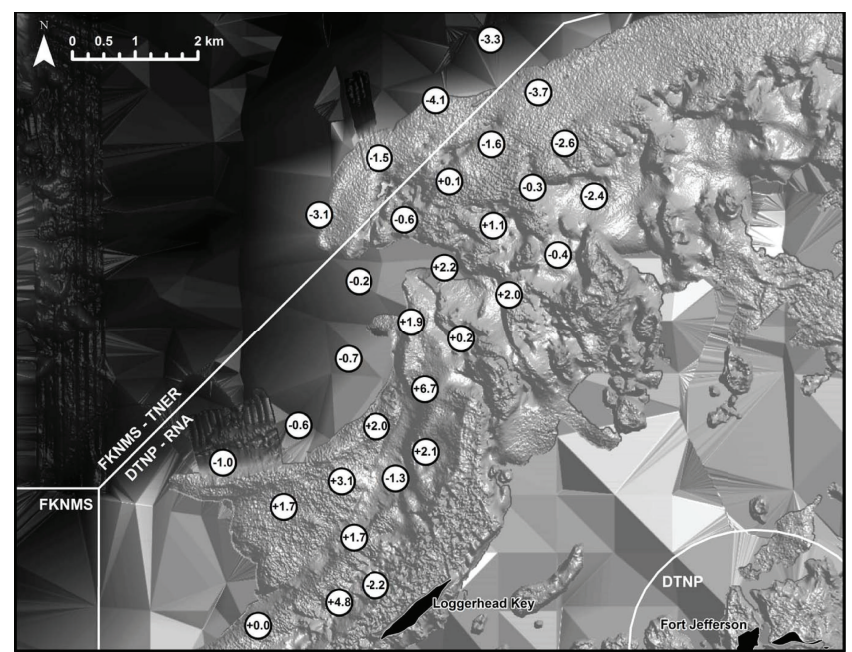

(b)

FIGURE 3: (a) Configuration of acoustic array relative to bathymetry $(\mathrm{m})$ and management boundaries and (b) systematic bias in estimated red grouper home range size attributable to location of individual home range centers. White circles indicate locations of simulated acoustic receivers; numbers within circles indicate percent of under- or overestimation by minimum convex polygon (MCP) home range method for simulated fish with home range center at location of circle. Inset in (a) shows study area relative to state and federal management boundaries. FKNMS: Florida Keys National Marine Sanctuary; DTNP: Dry Tortugas National Park; RNA: Research Natural Area; TNER: Tortugas North Ecological Reserve.

physics [27, 34, 35], (2) individual-based modeling developed based on optimal foraging theory [36], and (3) statistical modeling based on life history dynamics and behavioral ecology $[2,17]$. In this study, we employed a hybrid statisticalanalytic modeling process in an individual-based simulation environment to explore the sensitivity of commonly used statistical home range models to acoustic array design, tracking duration, and interspecific differences in fish home range movements. Our simulation model replicated basic features of observed reef fish space utilization patterns and was useful in identification of potential biases in home range estimates.

We generated MCP and KD home range estimates from empirical observations and simulation model outputs. Diagnostic testing suggested that statistical home range models were most robust for red grouper. This is not surprising, as field observation sample size for this stock was much higher than sample sizes for black grouper or mutton snapper. Bootstrapped simulations suggested that model parameterization was robust to small sample size, provided that sampled fish movements were representative of the population; thus, the results for black grouper and mutton snapper may be useful for the contrast they provide with red grouper and possibly also to understand some unique characteristics of the space requirements for these species.

Our home range simulation model parameters had simple biological and physical interpretations. When considered jointly with probability of movement $(\Psi)$, the mean of the exponential distribution for movement $(\lambda)$ is a proxy for overall mobility; a large $\lambda$ value indicates that the species is capable of moving substantial distances. Similarly, the concentration parameter $\kappa$ indicates affinity to a home range center; larger values of $\kappa$ imply higher affinities to a core home range. Red grouper affinity to a home range center was nearly three times that for black grouper. Simulations suggested that red grouper and black grouper have similarsized home ranges, but black grouper had a limited range and were less associated with core habitats. On the other hand, red grouper made periodic forays to nearby sites but often returned to a core habitat. Both groupers are ambush predators; however, black grouper are more piscivorous and less associated with the bottom [37, 38]. Mutton snapper exhibited higher mobility than groupers but maintained a strong association within a home range center. Mutton snapper in the Dry Tortugas are usually observed in low relief hard bottom habitats, patrolling sand channels along reef edges.

Comparing empirical animal location data with predictions from mechanistic or individual-based models is challenging [39], requiring an appropriate choice of sampling interval for discretizing continuous paths [34, 40]. We simplified this decision by creating a simulated array of acoustic receivers to replicate field detection patterns. As expected, simulated movement patterns were more homogeneous than empirically observed patterns. The duration and consistency of tracking across all individuals provided smoothing that may have masked individual patterns. In addition, many aspects of population dynamics, demographics, and life history influence fish movement patterns. Many of these factors were not captured by this simple modeling approach. For example, fish communities are comprised of both mobile and sedentary fractions [41], although it is unclear whether populations or individuals only exhibit one strategy or switch off occasionally throughout their lives [42]. Our model is most appropriate for describing the routine movements of an organism within a home range. 
TABLE 4: Availability and sensitivity of minimum convex polygon (MCP) and 95\% kernel density (KD) home range $\left(\mathrm{km}^{2}\right)$ estimates from acoustically tracked reef fish in Dry Tortugas, Florida (from [10]) to filtering criteria.

\begin{tabular}{|c|c|c|c|c|c|c|c|c|c|}
\hline \multirow{2}{*}{ Species } & \multirow{2}{*}{ Days } & \multirow{2}{*}{ Detections } & \multirow{2}{*}{ Asymptote } & \multirow{2}{*}{ Peripheral effect } & \multirow{2}{*}{$N$} & \multicolumn{2}{|c|}{$\mathrm{MCP}$} & \multicolumn{2}{|c|}{$95 \% \mathrm{KD}$} \\
\hline & & & & & & Mean & SE & Mean & SE \\
\hline Red grouper & All & All & All & All & 44 & 2.77 & 0.44 & 3.26 & 0.75 \\
\hline Red grouper & All & All & All & Low to moderate & 22 & 3.56 & 0.71 & 3.82 & 1.29 \\
\hline Red grouper & All & All & All & Low & 14 & 2.38 & 0.65 & 0.78 & 0.31 \\
\hline Red grouper & $>30$ & All & All & All & 38 & 2.04 & 0.33 & 1.71 & 0.43 \\
\hline Red grouper & $>60$ & All & All & All & 33 & 1.88 & 0.37 & 1.33 & 0.31 \\
\hline Red grouper & All & All & Yes or maybe & All & 32 & 2.22 & 0.38 & 2.39 & 0.73 \\
\hline Red grouper & All & All & Yes & All & 27 & 2.07 & 0.41 & 1.39 & 0.33 \\
\hline Red grouper & All & $>1000$ & All & All & 35 & 2.60 & 0.50 & 2.17 & 0.65 \\
\hline Red grouper & $>60$ & $>1000$ & Yes & Low & 12 & 2.46 & 0.76 & 0.73 & 0.36 \\
\hline Red grouper & $>30$ & All & Yes or maybe & Low to high & 28 & 2.08 & 0.39 & 1.74 & 0.51 \\
\hline Black grouper & All & All & All & All & 2 & 1.44 & 1.05 & 0.24 & 0.12 \\
\hline Black grouper & All & All & All & Low to moderate & 1 & 2.48 & & 0.12 & \\
\hline Black grouper & All & All & All & Low & 1 & 2.48 & & 0.12 & \\
\hline Black grouper & $>30$ & All & All & All & 2 & 1.44 & 1.05 & 0.24 & 0.12 \\
\hline Black grouper & $>60$ & All & All & All & 2 & 1.44 & 1.05 & 0.24 & 0.12 \\
\hline Black grouper & All & All & Yes or maybe & All & 2 & 1.44 & 1.05 & 0.24 & 0.12 \\
\hline Black grouper & All & All & Yes & All & 2 & 1.44 & 1.05 & 0.24 & 0.12 \\
\hline Black grouper & All & $>1000$ & All & All & 2 & 1.44 & 1.05 & 0.24 & 0.12 \\
\hline Black grouper & $>60$ & $>1000$ & Yes & Low & 1 & 2.48 & & 0.12 & \\
\hline Black grouper & $>30$ & All & Yes or maybe & Low to high & 2 & 1.44 & 1.05 & 0.24 & 0.12 \\
\hline Mutton snapper & All & All & All & All & 2 & 3.92 & 3.73 & 0.41 & 0.18 \\
\hline Mutton snapper & All & All & All & Low to moderate & 1 & 7.64 & & 0.58 & \\
\hline Mutton snapper & All & All & All & Low & 0 & & & & \\
\hline Mutton snapper & $>30$ & All & All & All & 1 & 7.64 & & 0.58 & \\
\hline Mutton snapper & $>60$ & All & All & All & 1 & 7.64 & & 0.58 & \\
\hline Mutton snapper & All & All & Yes or maybe & All & 1 & 7.64 & & 0.58 & \\
\hline Mutton snapper & All & All & Yes & All & 1 & 7.64 & & 0.58 & \\
\hline Mutton snapper & All & $>1000$ & All & All & 1 & 7.64 & & 0.58 & \\
\hline Mutton snapper & $>60$ & $>1000$ & Yes & Low & 0 & & & & \\
\hline Mutton snapper & $>30$ & All & Yes or maybe & Low to high & 1 & 7.64 & & 0.58 & \\
\hline
\end{tabular}

Note: estimates in italics were published in Farmer and Ault (2011). Estimates in bold represent the most conservative filtering criteria explored.

The multimodality observed in the input distributions of distances moved (Figures $1(\mathrm{a})-1(\mathrm{c})$ ) may be attributable to occasional large movements such as those associated with spawning migrations, low sample sizes for black grouper and mutton snapper, and the inclusion of individuals that did not appear to utilize a home range. Additional behavioral rules could be added to our model to capture biphasic reef fish movement strategies, such as ontogenetic migrations [43] or directed spawning migrations [10, 44, 45]. Alternatively, drawing movements from the observed distribution of movements rather than a smoothed statistical distribution might also provide greater heterogeneity in simulation output. The individual-based nature of the model design simplifies incorporation of these terms or other behaviors such as territoriality, visitation of foraging or cleaning sites, or avoidance of particular habitats. Although our data provided some hints that these factors might be important, the accurate parameterization of these additional behavioral terms would be challenging.

In general, simulation data indicated that home range estimates for observed red grouper were robust to movements beyond the array within the tracking duration because sample size was high enough to allow computations to be restricted to only include fish whose movements were constrained by the array. Additional analyses of empirical data failed to identify a relationship between estimated home range size from field observations and tracking duration. Analyses suggested that 3-4 months were a reasonable time period to obtain a reliable home range estimate for red grouper. Estimates of home range size for observed fish presented in Table 2 were constrained by the assumptions of statistical home range methods, namely, that home range estimates must reach 


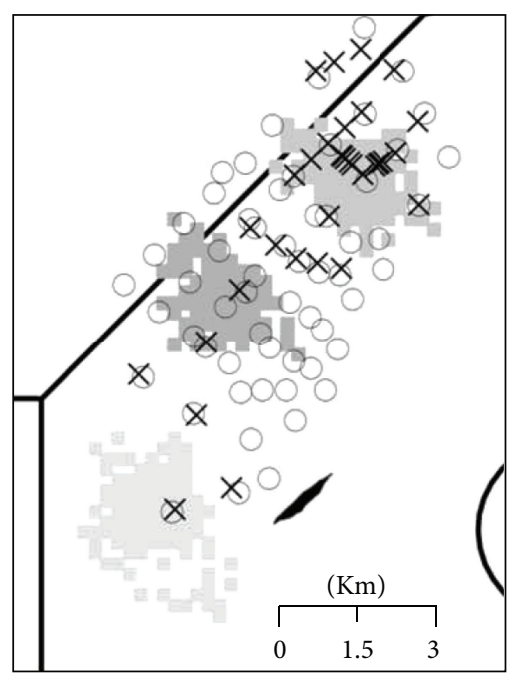

(a)

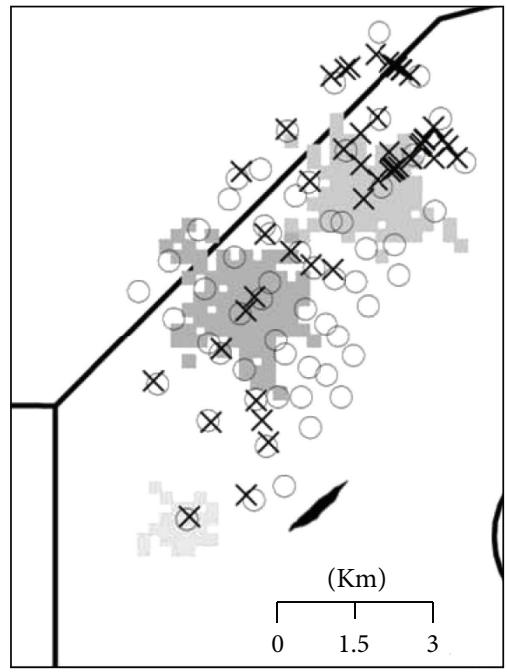

(d)

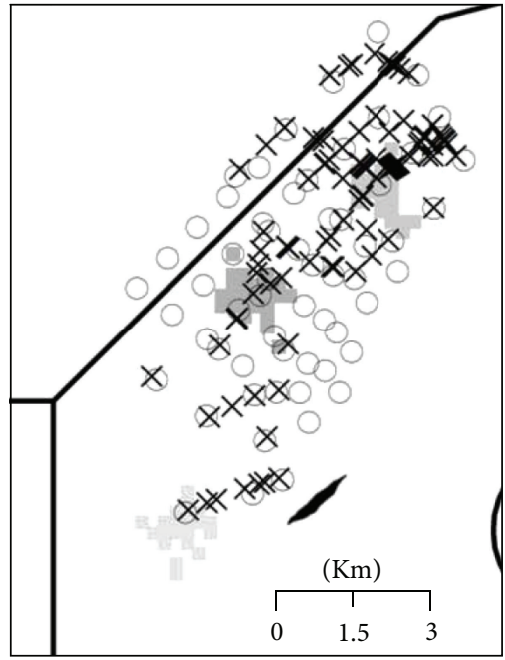

(g)

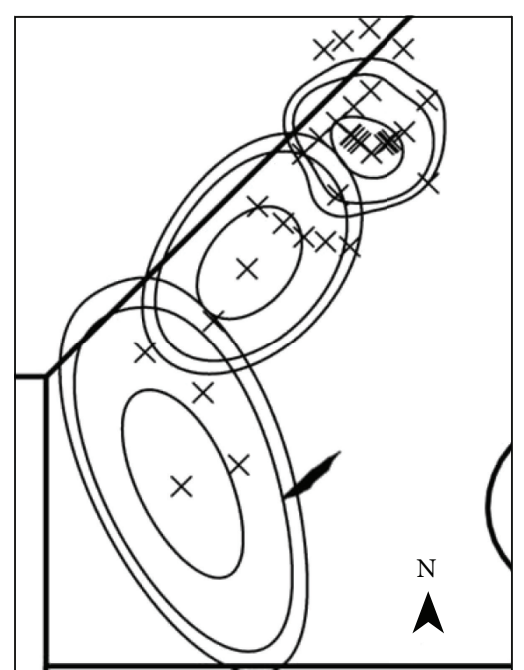

(b)

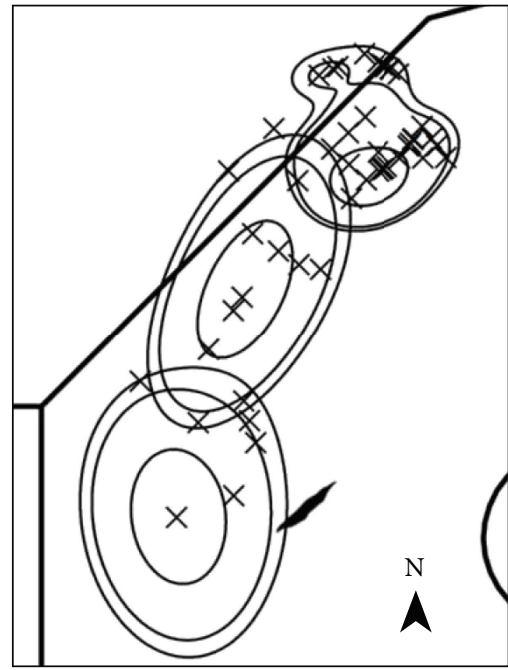

(e)

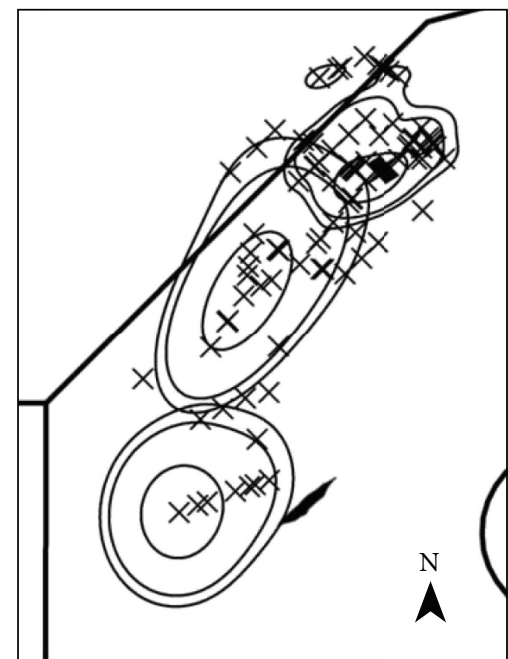

(h)

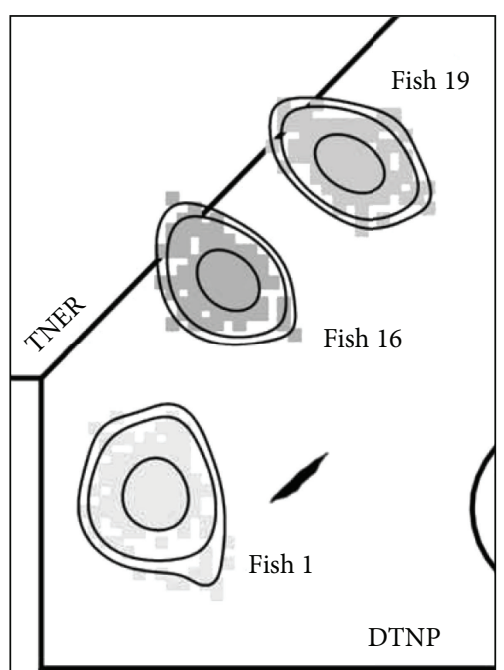

(c)

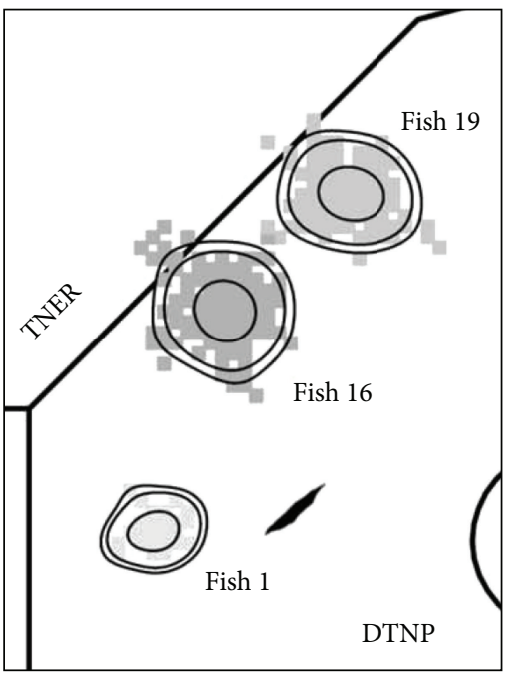

(f)

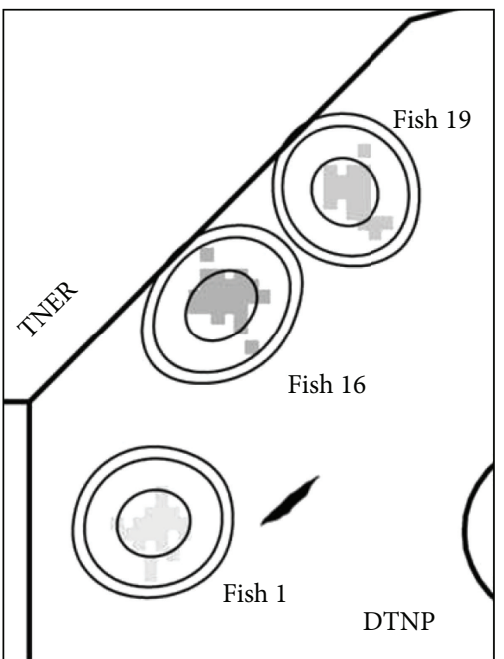

(i)

FIGURE 4: Configuration of simulated acoustic array (white circles) relative to actual path (gray squares) and simulated detections $(\times)$, with $95 \%, 90 \%$, and 50\% kernel density home ranges for simulated detections and actual simulation path of red grouper (a)-(c), black grouper (d)-(f), and mutton snapper (g)-(i). 


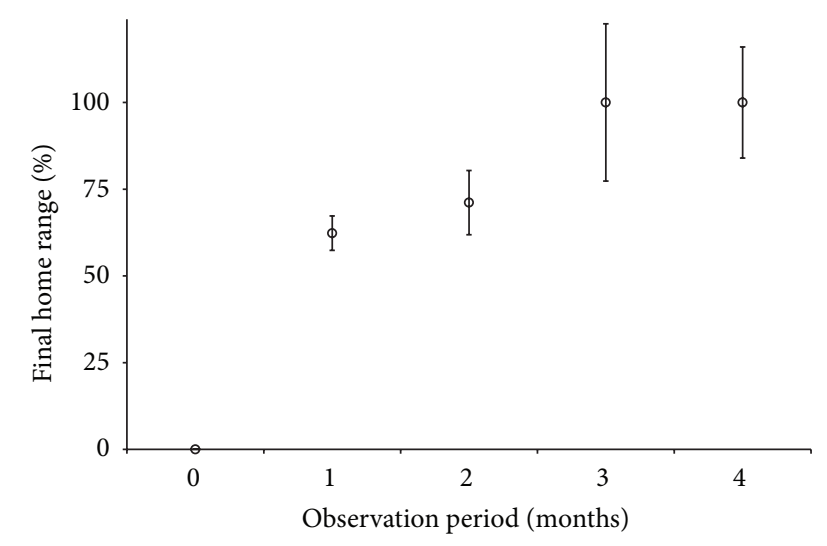

FIGURE 5: Least squares mean estimates from mixed model regression of percent of final minimum convex polygon (MCP) home range attained versus months of observation for red grouper. Bars denote standard error.

an asymptote when plotted over time as area-observation curves [46]. This led to the exclusion of 1 of 3 black grouper (33\%), 12 of 45 red grouper (27\%), and 1 of 2 mutton snapper (50\%). Most of these organisms were excluded because they moved outside the acoustic array. As such, their actual home ranges may have been larger than the individuals whose home ranges were estimated or these animals may have relocated their home ranges. Because our simulations incorporated movements and turning angles from all individuals tracked within each species, it is not surprising that simulated reef fish movements resulted in larger estimates of home range size.

Empirical observations suggested that exploited groupers and snappers require at least 1-2 months of monitoring before their space use reaches a visually recognizable asymptote [10], and 3-4 months is an optimum monitoring period. Estimated space use in a passive tracking study is a stepwise process, with substantial leaps in cumulative home range estimates each time a new receiver registers detections. The likelihood of detections at peripheral sites increased with time, tighter spacing of the array, and/or increased mobility of the fish. Our simulations suggested that researchers seeking to empirically estimate home range size should tag fish near the core of their acoustic array, attempt to track them for at least several months, and seriously consider the tradeoffs between desired positioning resolution and the risk of undetected movements outside the array ([28], this study). Unfortunately, most reef fish movement studies to date have been limited in both scope and scale (review in [10]). Researchers should also be aware that $100 \% \mathrm{MCP}$ and $95 \% \mathrm{KD}$ home range estimates can be substantially different, even when generated from the same data $([47,48]$, this study). Our simulation indicates that the MCP method is more robust than the $95 \% \mathrm{KD}$ with SCV bandwidth estimation to artifacts of acoustic tracking programs utilizing a passive array, such as high numbers of repeated positioning estimates from the same location. The common lament that MCP methods may overestimate home range size $[17,19-21]$ was not borne out in our study. The large $95 \% \mathrm{KD}$ estimates further stress the need for researchers to report home ranges using both methods and reporting the bandwidth estimation method and cell size for their KD estimation procedure, as these factors may have substantial impacts on resultant home range estimates.

Understanding the daily space requirements of exploited stocks is critical to the efficient design of no-take marine reserves (NTMRs). The protection afforded to a stock by an NTMR is dependent upon the fishing pressure surrounding the NTMR and the percentage of time the "protected" portion of the stock spends outside NTMR boundaries. Most models of marine protected areas either assume no fish movement or grossly oversimplify the dynamics of fish mobility [4959]. The simple modeling process employed in this study was based on the concept that mobility of an organism is a process of three linked behaviors: probability of movement, distance moved, and turning angle. An organism that moves frequently (e.g., high $\psi$ ) or moves large distances (e.g., high 1) may not be "highly-mobile" in the strictest sense if it has a high affinity to a home range center (e.g., high $\kappa$ ) that restricts its overall dispersal; however, the percentage of time spent beyond the bounds of the protected area becomes a critical consideration in NTMR planning. The simple formulation of our model allows for easy manipulation of home range affinity and distances moved, allowing for easy extension to various movement strategies and extrapolation to new species as data become available. Our model provided useful upper bounds for empirically observed home range estimates. It could be easily extended into spatial population dynamic simulation models to assess NTMR performance or suggest appropriate NTMR designs relative to the spatial scale of movements.

\section{Conflict of Interests}

The authors declare that there is no conflict of interests regarding the publication of this paper.

\section{Acknowledgments}

This research was supported by National Park Service CESU Contract H5000065040-J5281060165 and NOAA NMFS Coral Reef Conservation Program Grants NA17RJ1226 and NA08OAR4320892. This material is based upon work supported by the National Science Foundation under Grant No. EAR 1204752. Graduate support was provided to Nicholas A. Farmer by an ASEE National Defense Science and Engineering Graduate Fellowship and a University of Miami Doctoral Fellowship. The authors thank Superintendent Dan Kimball and Assistant Superintendent Bob Howard of Dry Tortugas National Park and Billy Causey of the Florida Keys National Marine Sanctuary, for funding, permits, and access to resources. They also thank the following for additional support: Florida Foundation for Responsible Angling; International Light Tackle Tournament Association; International Women's Fishing Association Ryan Kelley Memorial Scholarship; Marine Technology Society; PADI Project AWARE; SEASPACE; Yamaha Contender Miami Billfish Tournament; University of Miami Small Boats Program; Yankee Fleet of Key West; Costa del Mar; National Marine Fisheries 
Service; G. Kelley; S. Donahue; The Calloway Family; American Institute of Fishery Research Biologists; United States Geological Survey; Stock Island Oceanside Marina; Andy Griffiths Charters of Key West, Florida; D. B. Olson, N. M. Ehrhardt, and J. W. McManus of University of Miami; and the authors' many field volunteers. All research was in full compliance with the University of Miami Institutional Animal Care and Use Committee.

\section{References}

[1] E. T. Seton, Life Histories of Northern Animals, vol. 1, Charles Scribner's Sons, New York, NY, USA, 1909.

[2] W. H. Burt, "Territoriality and home range concepts as applied to mammals," Journal of Mammalogy, vol. 24, pp. 246-352, 1943.

[3] S. Harris, W. J. Cresswell, P. G. Forde, W. J. Trewhella, T. Woollard, and S. Wray, "Home-range analysis using radio-tracking data-a review of problems and techniques particularly as applied to the study of mammals," Mammal Review, vol. 20, no. 2-3, pp. 97-123, 1990.

[4] D. L. Kramer and M. R. Chapman, "Implications of fish home range size and relocation for marine reserve function," Environmental Biology of Fishes, vol. 55, no. 1-2, pp. 65-79, 1999.

[5] T. Bell and D. L. Kramer, "Territoriality and habitat use by juvenile blue tangs, Acanthurus coeruleus," Environmental Biology of Fishes, vol. 58, no. 4, pp. 401-409, 2000.

[6] N. Eristhee and H. A. Oxenford, "Home range size and use of space by Bermuda chub Kyphosus sectatrix (L.) in two marine reserves in the Soufrière Marine Management Area, St Lucia, West Indies," Journal of Fish Biology, vol. 59, pp. 129-151, 2001.

[7] S. K. Bolden, Nassau grouper (Epinephelus striatus, Pisces: Serranidae) movement in the Bahamas, as determined by ultrasonic telemetry [Ph.D. dissertation], University of Miami, Miami, Fla, USA, 2001.

[8] G. Lembo, M. T. Spedicato, F. Økland et al., "A wireless communication system for determining site fidelity of juvenile dusky groupers Epinephelus marginatus (Lowe, 1834) using coded acoustic transmitters," Hydrobiologia, vol. 483, pp. 249257, 2002.

[9] E. Baras, B. Togola, B. Sicard, and V. Bénech, "Behaviour of tigerfish Hydrocynus brevis in the River Niger, Mali, as revealed by simultaneous telemetry of activity and swimming depth," Hydrobiologia, vol. 483, pp. 103-110, 2002.

[10] N. A. Farmer and J. S. Ault, "Grouper and snapper movements and habitat use in Dry Tortugas, Florida," Marine Ecology Progress Series, vol. 433, pp. 169-184, 2011.

[11] G. A. Meester, A. Mehrotra, J. S. Ault, and E. K. Baker, "Designing marine reserves for fishery management," Management Science, vol. 50, no. 8, pp. 1031-1043, 2004.

[12] J. A. Bohnsack, J. S. Ault, and B. Causey, "Why have no-take marine protected areas?" American Fisheries Society Symposium, vol. 2004, no. 42, pp. 185-193, 2004.

[13] J. S. Ault, J. A. Bohnsack, S. G. Smith, and J. Luo, “Towards sustainable multispecies fisheries in the Florida, USA, coral reef ecosystem," Bulletin of Marine Science, vol. 76, no. 2, pp. 595622, 2005.

[14] J. S. Ault, S. G. Smith, J. A. Bohnsack, J. Luo, D. E. Harper, and D. B. McClellan, "Building sustainable fisheries in Florida's coral reef ecosystem: positive signs in the dry tortugas," Bulletin of Marine Science, vol. 78, no. 3, pp. 633-654, 2006.
[15] J. S. Ault, S. G. Smith, J. A. Bohnsack et al., "Assessing coral reef fish changes and marine reserve dynamics in the Dry Tortugas, Florida USA," Fisheries Research, vol. 144, pp. 28-37, 2013.

[16] E. P. Odum and E. J. Kuenzler, "Measurement of territory and home range size in birds," Auk, vol. 72, pp. 128-137, 1955.

[17] B. J. Worton, "Kernel methods for estimating the utilization distribution in home- range studies," Ecology, vol. 70, no. 1, pp. 164-168, 1989.

[18] C. M. St. Mary, C. W. Osenberg, T. K. Frazer, and W. J. Lindberg, "Stage structure, density dependence and the efficacy of marine reserves," Bulletin of Marine Science, vol. 66, no. 3, pp. 675-690, 2000.

[19] K. R. Dixon and J. A. Chapman, "Harmonic mean measure of animal activity areas," Ecology, vol. 61, no. 5, pp. 1040-1044, 1980.

[20] R. A. Powell, "Animal home ranges and territories and home range estimators," in Research Techniques in Animal Ecology: Controversies and Consequences, L. Boitani and T. Fuller, Eds., pp. 65-110, Columbia University Press, New York, NY, USA, 2000.

[21] M. A. Burgman and J. C. Fox, "Bias in species range estimates from minimum convex polygons: implications for conservation and options for improved planning," Animal Conservation, vol. 6, no. 1, pp. 19-28, 2003.

[22] H. L. Beyer, "Geospatial Modelling Environment (Version 0. 6. 0. 0)," (software), 2012, http://www.spatialecology.com/gme/.

[23] D. E. Seaman and R. A. Powell, "An evaluation of the accuracy of kernel density estimators for home range analysis," Ecology, vol. 77, no. 7, pp. 2075-2085, 1996.

[24] T. Duong and M. L. Hazelton, "Convergence rates for unconstrained bandwidth matrix selectors in multivariate kernel density estimation," Journal of Multivariate Analysis, vol. 93, no. 2, pp. 417-433, 2005.

[25] P. Holgate, "Random walk models for animal behavior," in Statistical Ecology: Sampling and Modeling Biological Popuations and Population Dynamics, G. Patil, E. Pielou, and W. Walters, Eds., vol. 2 of Penn State Statistics, pp. 1-12, Penn State University Press, University Park, PA, USA, 1971.

[26] A. Okubo, Diffusion and Ecological Problems: Mathematical Models, Springer, Berlin, Germany, 1980.

[27] P. R. Moorcroft and M. A. Lewis, Mechanistic Home Range Analysis, Princeton University Press, Princeton, NJ, USA, 2006.

[28] N. A. Farmer, J. S. Ault, S. G. Smith, and E. C. Franklin, "Methods for assessment of short-term coral reef fish movements within an acoustic array," Movement Ecology, vol. 1, article 7, 2013.

[29] J. Fox, Applied Regression Analysis and Generalized Linear Models, Sage, Los Angeles, CA, USA, 2009.

[30] M. J. North, N. T. Collier, and J. R. Vos, "Experiences creating three implementations of the repast agent modeling toolkit," ACM Transactions on Modeling and Computer Simulation, vol. 16, no. 1, pp. 1-25, 2006.

[31] N. Collier, "RePast: An Agent-based Ecological Modeling Toolkit," Available at repast.sourceforge.net, 2008.

[32] R. G. Ford, "Home range in a patchy environment: optimal foraging predictions," Integrative and Comparative Biology, vol. 23, no. 2, pp. 315-326, 1983.

[33] L. Börger, B. D. Dalziel, and J. M. Fryxell, "Are there general mechanisms of animal home range behaviour? A review and prospects for future research," Ecology Letters, vol. 11, no. 6, pp. 637-650, 2008. 
[34] P. Turchin, Quantitative Analysis of Movement, Sinauer Associates, Sunderland, Mass, USA, 1998.

[35] A. Okubo and S. Levin, Diffusion and Ecological Problems: Modern Perspectives, Springer, Berlin, Germany, 2001.

[36] M. S. Mitchell and R. A. Powell, "A mechanistic home range model for optimal use of spatially distributed resources," Ecological Modelling, vol. 177, no. 1-2, pp. 209-232, 2004.

[37] C. L. Smith, "Synopsis of biological data on groupers (Epinephelus and allied genera) of the western North Atlantic," FAO Fisheries Biology Synopsis, no. 23, 61 pages, 1961.

[38] J. E. Randall, "Food habits of reef fishes of the West Indies," Studies in Tropical Oceanography, University of Miami, vol. 5, pp. 665-847, 1967.

[39] S. Coscoy, E. Huguet, and F. Amblard, "Statistical analysis of sets of random walks: how to resolve their generating mechanism," Bulletin of Mathematical Biology, vol. 69, pp. 2467-2492, 2007.

[40] S. Benhamou, "Detecting an orientation component in animal paths when the preferred direction is individual-dependent," Ecology, vol. 87, pp. 518-528, 2006.

[41] J. L. Funk, "Movement of stream fishes in Missouri," Transactions of the American Fisheries Society, vol. 85, pp. 39-57, 1957.

[42] E. B. Smithson and C. E. Johnston, "Movement patterns of stream fishes in a Ouachita Highlands stream: an examination of the restricted movement paradigm," Transactions of the American Fisheries Society, vol. 128, no. 5, pp. 847-853, 1999.

[43] K. C. Lindeman, R. Pugliese, G. T. Waugh, and J. S. Ault, "Developmental patterns within a multispecies reef fishery: management applications for essential fish habitats and protected areas," Bulletin of Marine Science, vol. 66, no. 3, pp. 929956, 2000.

[44] A.-M. Eklund, D. B. McClellan, and D. E. Harper, "Black grouper aggregations in relation to protected areas within the Florida Keys National Marine Sanctuary," Bulletin of Marine Science, vol. 66, no. 3, pp. 721-728, 2000.

[45] M. L. Burton, K. J. Brennan, R. C. Muñoz, and R. O. Parker Jr., "Preliminary evidence of increased spawning aggregations of mutton snapper (Lutjanus analis) at Riley's Hump two years after establishment of the Tortugas South Ecological Reserve," Fishery Bulletin, vol. 103, no. 2, pp. 404-410, 2005.

[46] J. W. Laundré and B. L. Keller, "Home-range size of coyotes: a critical review," The Journal of Wildlife Management, vol. 48, no. 1, pp. 127-139, 1984.

[47] T. W. Schoener, "An empirically based estimate of home range," Theoretical Population Biology, vol. 20, no. 3, pp. 281-325, 1981.

[48] M. D. Samuel, D. J. Pierce, and E. O. Garton, "Identifying areas of concentrated use within the home range," Journal of Animal Ecology, vol. 54, no. 3, pp. 711-719, 1985.

[49] T. Polacheck, "Year-round closed areas as a management tool," Natural Resource Modeling, vol. 4, no. 3, pp. 327-354, 1990.

[50] E. E. Demartini, "Modeling the potential of fishery reserves for managing Pacific coral reef fishes," Fishery Bulletin, vol. 91, no. 3, pp. 414-427, 1993.

[51] A. Rakitin and D. L. Kramer, "Effect of a marine reserve on the distribution of coral reef fishes in Barbados," Marine Ecology Progress Series, vol. 131, no. 1-3, pp. 97-113, 1996.

[52] U. R. Sumaila, "Protected marine reserves as fisheries management tools: a bioeconomic analysis," Fisheries Research, vol. 37, no. 1-3, pp. 287-296, 1998.

[53] M. J. Fogarty, "Essential habitat, marine reserves and fishery management," Trends in Ecology and Evolution, vol. 14, no. 4, pp. 133-134, 1999.
[54] S. Guénette and T. J. Pitcher, "An age-structured model showing the benefits of marine reserves in controlling overexploitation," Fisheries Research, vol. 39, no. 3, pp. 295-303, 1999.

[55] Y. Xiao, "An individual-based approach to evaluating experimental designs for estimating rates of fish movement from tag recoveries," Ecological Modelling, vol. 128, no. 2-3, pp. 149-163, 2000.

[56] T. J. Pitcher, R. Watson, N. Haggan et al., "Marine reserves and the restoration of fisheries and marine ecosystems in the South China Sea," Bulletin of Marine Science, vol. 66, no. 3, pp. 543$566,2000$.

[57] J. Sladek Nowlis and C. M. Roberts, "Fisheries benefits and optimal design of marine reserves," Fishery Bulletin, vol. 97, no. 3, pp. 604-616, 1999.

[58] R. A. Watson, J. Alder, and C. Walters, "A dynamic mass-balance model for marine protected areas," Fish and Fisheries, vol. 1, pp. 94-98, 2000.

[59] J. N. Sanchirico and J. E. Wilen, "Bioeconomics of spatial exploitation in a patchy environment," Journal of Environmental Economics and Management, vol. 37, no. 2, pp. 129-150, 1999. 

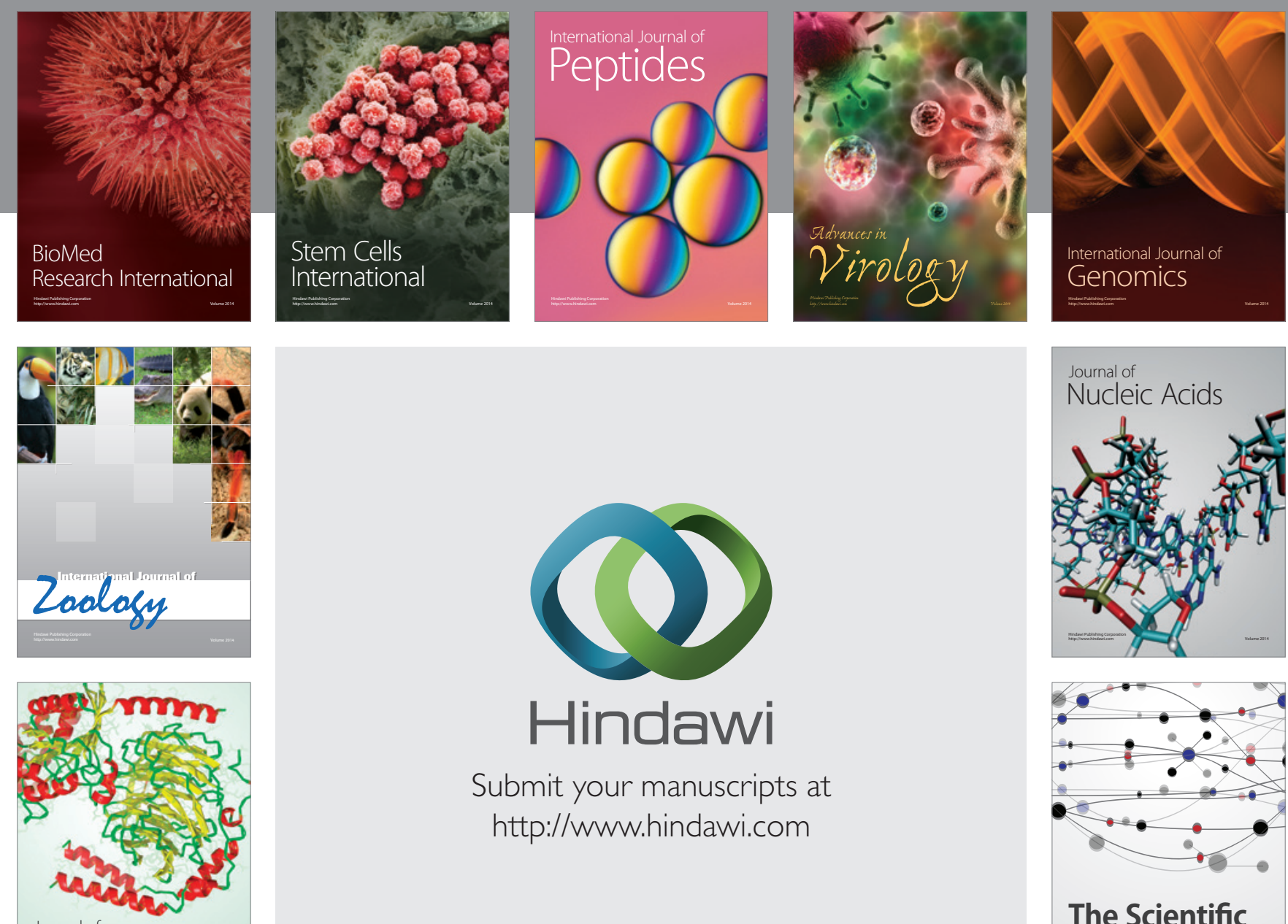

Submit your manuscripts at

http://www.hindawi.com

Journal of
Signal Transduction
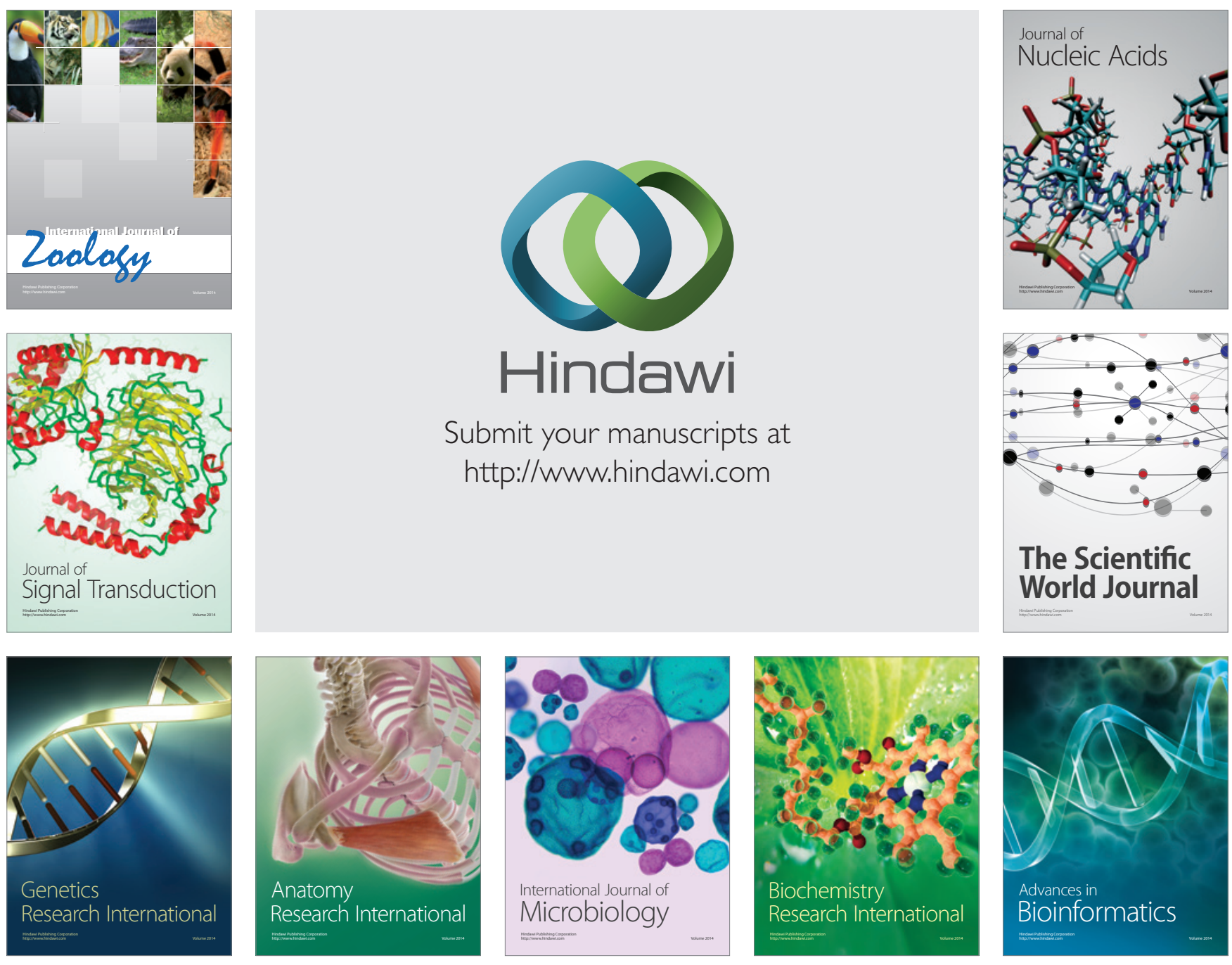

The Scientific World Journal
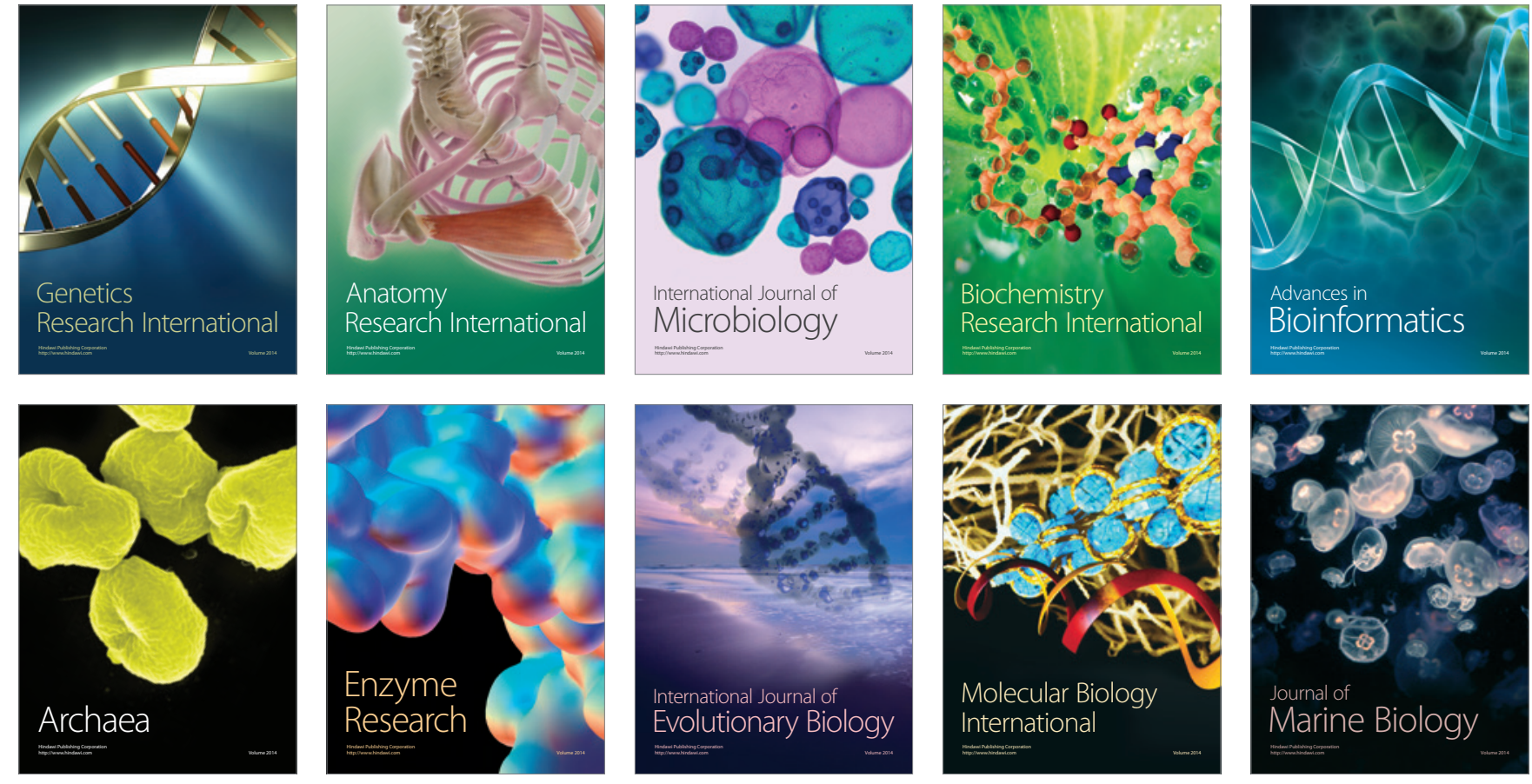